\title{
GTK Tyrosine Kinase-induced Alteration of IRS-protein Signalling in Insulin Producing Cells
}

\author{
Cecilia Annerén ${ }^{1}$ and Michael Welsh \\ Department of Medical Cell Biology, Uppsala University, Uppsala, Sweden \\ Contributed by: D. Steiner. Accepted September 9, 2002
}

\begin{abstract}
Background: Insulin receptor substrate proteins (IRS) mediate various effects of insulin, including regulation of glucose homeostasis, cell growth and survival. To understand the underlying mechanisms explaining the effects of the Src-related tyrosine kinase GTK on $\beta$-cell proliferation and survival, insulin-signalling pathways involving IRS-1 and IRS-2 were studied in islet cells and RINm5F cells overexpressing wild-type and two different mutants of the SRC-related tyrosine kinase GTK.

Materials and Methods: Islets isolated from transgenic mice and RINm5F cells overexpressing wild-type and mutant GTK were analysed for IRS-1, IRS-2, SHB, AKT and ERK phosphorylation/activity by Western blot analysis.

Results: RINm5F cells expressing the kinase active mutant Y504F-GTK and islet cells from GTK ${ }^{\mathrm{Y504F}}$-transgenic mice exhibited reduced insulin-induced tyrosine phosphorylation of IRS-1 and IRS-2. In RINm5F cells, the diminished IRS-phosphorylation was accompanied by a
\end{abstract}

reduced insulin-stimulated activation of phosphatidylinositol 3-kinase (PI3K), AKT and Extracellular SignalRegulated Kinase, partly due to an increased basal activity. In addition, increased tyrosine phosphorylation of the SHB SH2 domain-adaptor protein and its association with IRS-2, IRS-1 and focal adhesion kinase was observed in these cells. RINm5F cells overexpressing wild-type GTK also exhibited reduced activation of IRS-2, PI3K and AKT, whereas cells expressing a GTK mutant with lower kinase activity $\left(\mathrm{GTK}^{\mathrm{Y} 394 \mathrm{~F}}\right)$ exhibited insignificantly altered responses to insulin compared to the mock transfected cells. Moreover, GTK was shown to associate with and phosphorylate SHB in transiently transfected COS-7 cells, indicating that SHB is a specific substrate for GTK.

Conclusions: The results suggest that GTK signals via SHB to modulate insulin-stimulated pathways in $\beta$ cells and this may explain previous results showing an increased $\beta$-cell mass in GTK-transgenic mice.

\section{Introduction}

Secretion of insulin from pancreatic $\beta$ cells tightly regulates glucose homeostasis by stimulating glucose uptake in peripheral tissues and inhibiting hepatic glucose production. It is presently clear that the active $\beta$-cell mass is a function of replication of pre-existing $\beta$ cells, $\beta$-cell neogenesis and $\beta$-cell survival and a significant amount of research has been conducted in order to elucidate the signalling pathways regulating each of these. Protein kinases play an important role in the regulation of cell growth, differentiation and survival and in search of protein tyrosine kinases expressed in $\beta$ cells, the SRC-related tyrosine kinase GTK (BSK/IYK) was characterised (1). Tyr-504 in the GTK C-terminal tail is homologous to Tyr-527 in

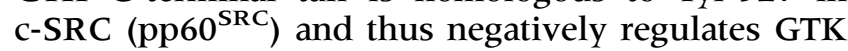
kinase activity (2). In contrast, Tyr-394 is the main autophosphorylation site in GTK and in analogy with Tyr-416 in c-SRC may be a positive regulator of GTK kinase activity. Introduction of a Y416F-mutation in c-SRC eliminates its partial transforming activity and

${ }^{1}$ Present address: Howard Hughes Medical Institute, Department of Molecular Cell Biology, Harvard University, Cambridge, MA, USA. Address correspondence and reprint requests to: Michael Welsh, Department of Medical Cell Biology, Box 571, Biomedical Centre, S-751 23 Uppsala, Sweden. Phone: +46-18-4714447; fax: +46-18-556401; e-mail: michael.welsh@medcellbiol.uu.se. suppresses the ability of c-SRC to be activated by Tyr527 dephosphorylation (3). Islets isolated from transgenic mice expressing GTK $^{\mathrm{Y} 504 \mathrm{~F}}$ under the control of the rat insulin 1 promoter exhibit an increased $\beta$-cell mass as a consequence of a larger pancreas and an increased relative $\beta$-cell area (4). Moreover GTKtransgenic mice show increased cytokine-induced cytotoxicity and elevated basal activity of Extracellular Signal-Regulated Kinase (ERK). GTK has previous been suggested to signal via the SRC homology 2 (SH2)-domain protein SHB to induce neurite outgrowth in PC12 cells (5). SHB is an adaptor protein with proline-rich motifs in its $\mathrm{N}$-terminus, a central phosphotyrosine binding domain, several potential tyrosine phosphorylation sites and a C-terminal SH2 domain $(6,7)$. Transgenic mice, expressing SHB under the control of the insulin promoter, show similar features as the GTK-transgenic mice, with an increased $\beta$-cell mass and increased cytokine-induced islet cell death (8), suggesting that GTK might signal via SHB in insulin producing cells.

Some reports suggest that insulin regulates its own secretion in an autocrine/paracrine fashion $(9,10)$ but the role of insulin action in $\beta$ cells is still unclear. The cellular response to insulin requires to a large extent tyrosine phosphorylation of the insulin receptor substrates, which are cytosolic docking proteins that mediate various effects of insulin, 
including regulation of glucose homeostasis, cell growth and survival (11-15). IRS- 1 and -2 bind several proteins including GRB2/SOS and phosphatidylinositol-3 kinase (PI3K). The binding of GRB2/SOS to IRS induces activation of the RASERK 1/2 pathway whereas PI3K activation leads to the phosphorylation of phosphatidylinositols (PI) and subsequent AKT activation. AKT, in turn, when phosphorylated by PDK1 in position Thr-308 and autophosphorylated in position Ser-473, promotes cell survival and protein synthesis (16). Disruption of the IRS- 1 gene causes a mild degree of peripheral insulin resistance, which is compensated for by an increased $\beta$-cell mass, whereas inactivation of the IRS- 2 gene reduces the number of $\beta$ cells and causes type 2 diabetes (17-21). A tissue-specific knockout of the insulin receptor in $\beta$ cells impairs insulin secretion in response to glucose, suggesting that insulin signalling is important for glucose sensing by the pancreatic $\beta$ cells (22).

SHB-overexpression in insulin producing cells causes altered insulin signalling through the IRSproteins in insulin producing cells (23a). The present study was conducted in order to address whether the effects of GTK in $\beta$ cells on ERK activity, growth and survival could be reflected to the IRSsignalling system and SHB. For this purpose we assessed IRS-phosphorylation in response to insulin in islets from $\mathrm{GTK}^{\mathrm{Y} 504 \mathrm{~F}}$-transgenic and control mice. Moreover, pathways downstream of the IRSproteins were studied in RINm5F cells stably overexpressing wild type, Y504F-mutated and Y394Fmutated GTK.

\section{Materials and Methods}

\section{Cells}

RINm5F cell clones, stably overexpressing GTK $\left(\mathrm{GTK}^{\mathrm{Wt}}, \mathrm{GTK}^{\mathrm{Y} 504 \mathrm{~F}}\right)$ and control clones transfected with the neomycin resistance gene (neo- 1 and neo-2), were generated previously (2). Y394F-mutated gtk cDNA was obtained by sequential polymerase chain reaction (PCR) of wild type $g t k$ CDNA inserted into the pcDNA 3.1 (-)/Myc-His B vector (InVitrogen, Carlsbad, CA) using the following primers: 5'-GATAATGAAGACATCTTTGAATCTAAACACG-3' (nt 16521683), 5'-TCTAGATAGTTTATGAAGTTATTTG-3' (nt 2008-2027), 5'-GTAAAGCTTGTGGGGAGAGG-3' (nt 431-450) and 5'-CGTGTTTAGATTCAAAGATGTCTTCATTATC-3' (nt 1652-1683). The final mutated PCRproduct was purified by electroelution and ligated into the pT7Blue-vector (Novagen, Madison, WI). After subcloning, the $g t k$-fragment was inserted into the XbaI site of the pcDNA 3.1 (-)/Myc-His B vector and transfected into RINm5F cells using 5\% LipofectAMINE $^{\text {TM }}$ (Gibco BRL, Gaithersburg, MD) and $9 \mu \mathrm{g}$ DNA (23). The cells were cultured with $0.6 \mathrm{mg} / \mathrm{ml}$ Geneticin (G418; Gibco BRL) and clones were isolated and cultured as previously described (2). Clones were analysed for GTK mRNA and protein expression. Growing RINm5F cells were trypsinised every 3-5 days and subcultured in RPMI $1640+10 \%$ Foetal Calf Serum (FCS).

COS-7 cells ( $5 \mathrm{~cm}$ dishes) were cultured to subconfluence in DMEM $+10 \%$ FCS before transient transfection using 3\% LipofectAMINE ${ }^{\mathrm{TM}}$ and $3 \mu \mathrm{g}$ DNA (full length wild-type shb inserted into pcDNA 1 and/or full length Y504F-mutated gtk inserted into pcDNA $3.1(-) /$ Myc-His B in $1.5 \mathrm{ml}$ serum-free DMEM for $2 \mathrm{~h}$ at $37^{\circ} \mathrm{C}$. The transfected COS-7 cells were cultured for $48 \mathrm{~h}$ in DMEM $+10 \%$ FCS before co-immunoprecipitation studies.

The GTK-transgenic mice were generated as previously described (4) and islets were isolated, by collagenase digestion, from GTK-transgenic and CBA control mice of both genders at approximately 4 months of age. The islets were pre-cultured in $11.1 \mathrm{mM}$ glucose for 2 days before experimentation and all cells (islets and RINm5F cells) were serumdeprived for $60 \mathrm{~min}$ before stimulation with insulin (stock: $10 \mathrm{mg} / \mathrm{ml}$ insulin in $30 \mathrm{mM} \mathrm{HCl}$; RINm5F cells were stimulated with $0.1 \mu \mathrm{g} / \mathrm{ml}$ and islets with $10 \mu \mathrm{g} / \mathrm{ml}$ insulin) or $\mathrm{HCl}$, without insulin, as control. The Uppsala Animal Ethics Committee approved the animal experimentation.

\section{Immunoprecipitation and Western Blot Analysis}

Subconfluent cultures $(10 \mathrm{~cm}$ dishes $)$ of control (neo) RINm5F cells or RINm5F cells expressing mutated or wild type GTK were stimulated with insulin as described above. After washing the cells with cold PBS they were lysed in $100 \mathrm{mM}$ Tris (pH 8.0), $150 \mathrm{mM} \mathrm{NaCl}, 1 \%$ Triton X-100, $5 \mathrm{mM}$ EDTA, $5 \mathrm{mM}$ DTT, $1 \mathrm{mM} \mathrm{Na} \mathrm{VO}_{4}, 1 \mathrm{mM}$ PMSF and $50 \mu \mathrm{M}$ leupeptin. The lysate was pre-cleared by centrifugation and immunoprecipitated with anti-IRS-1, anti-IRS-2 (Upstate Biotechnology, Lake Placid, NY) or anti-SHB antibody (made according to (24)). The immuno-complexes were precipitated with protein-A sepharose (Amersham Pharmacia Biotech, Uppsala, Sweden), washed with PBS $+1 \%$ Triton, denatured by boiling in SDS- $\beta$-mercapthoethanol sample buffer and subjected to Western blot analysis for phosphotyrosine (4G10, Upstate Biotechnology, Lake Placid, NY), IRS-1, IRS-2, SHB or phospho-FAK (Tyr397) (Transduction Laboratories, Lexington, KY). The amount of phosphorylated protein was quantified by densitometric scanning using Kodak Digital Science ID software (Eastman Kodak, Rochester, NY) and normalised against the total amount of protein.

Transiently transfected COS-7 cells (SHB, $\mathrm{GTK}^{\mathrm{Y} 504 \mathrm{~F}}$ or SHB + GTK ${ }^{\mathrm{Y} 504 \mathrm{~F}}$ ) were lysed, immunoprecipitated with anti-GTK and anti-SHB antibody and subjected to Western blotting for SHB, GTK and phosphotyrosine.

\section{In Vitro Kinase Assay}

RINm5F clones were cultured to subconfluence and $\mathrm{Na}_{3} \mathrm{VO}_{4}(0.1 \mathrm{mM})$ was added $15 \mathrm{~min}$ prior to harvest. GTK was immunoprecipitated and subjected to an 
in vitro kinase assay as described previously (23). In short, cells were lysed and the nuclei were removed by centrifugation. GTK was precipitated with GTK antiserum and Protein A Sepharose. The beads were incubated with [ $\gamma-{ }^{32}$ P]ATP for $15 \mathrm{~min}$ at room temperature and the reaction was stopped by addition of SDS-sample buffer. The samples were run on a $7.5 \%$ SDS-polyacrylamide gel and subjected to Western blotting for GTK or autoradiography using Hyperfilm $^{\text {TM }}$ MP (Amersham Pharmacia Biotech).

\section{PI3K Assay}

Serum starved RINm5F cells (Subconfluent in $10 \mathrm{~cm}$ dishes) were stimulated with insulin and cells were washed and lysed in $100 \mathrm{mM}$ Tris (pH 8.0), $150 \mathrm{mM}$ $\mathrm{NaCl}, 1 \%$ Triton X-100, $5 \mathrm{mM}$ EDTA, $5 \mathrm{mM}$ DTT, $1 \mathrm{mM} \mathrm{Na} \mathrm{VO}_{4}, 1 \mathrm{mM}$ PMSF and $50 \mathrm{mM}$ leupeptin. The lysate was pre-cleared by centrifugation and then used for immunoprecipitation using an antiphosphotyrosine antibody (PY20) (Transduction Laboratories). The immuno-complexes were bound to Protein A-Sepharose, washed twice with PBS containing $1 \%$ NP-40 and 1 mM DTT followed by two washes with $100 \mathrm{mM}$ Tris (pH 7.6), $500 \mathrm{mM}$ $\mathrm{LiCl}$ and $1 \mathrm{mM}$ DTT. The immuno-complexes were washed once with $10 \mathrm{mM}$ Tris $(\mathrm{pH} 7.6), 100 \mathrm{mM}$ $\mathrm{NaCl}, 1 \mathrm{mM}$ DTT, followed by incubation for $10 \mathrm{~min}$ in $10 \mathrm{mM}$ Tris (pH 7.6), $100 \mathrm{mM} \mathrm{NaCl}, 1 \mathrm{mM}$ DTT and $0.25 \mathrm{mg} / \mathrm{ml}$ phosphatidylinositol (PI). The reaction was initiated by addition of $10 \mathrm{mM} \mathrm{MgCl}_{2}$, $20 \mathrm{mM}$ Hepes (pH 7.6), $50 \mu \mathrm{M}$ ATP and $5 \mu \mathrm{Ci}$ of $\gamma-\left[{ }^{32} \mathrm{P}\right]$-ATP (final concentrations in $50 \mu \mathrm{l}$ ). After 10 minutes, the reaction was terminated by the addition of $15 \mu \mathrm{l} 4 \mathrm{M} \mathrm{HCl}$ and $130 \mu \mathrm{l}$ chloroform/methanol $(1: 1, \mathrm{v} / \mathrm{v})$. Phospholipids were extracted as previously described (25) and separated on silica TLC plates (Merck, Darmstadt, Germany) using $\mathrm{CHCl}_{3}: \mathrm{CH}_{3} \mathrm{OH}: \mathrm{NH}_{4} \mathrm{OH}: \mathrm{H}_{2} \mathrm{O}$ (600:470:20:113, $\mathrm{v} / \mathrm{v})$ as solvent. Radioactive spots were detected with autoradiography and quantified by densitometric scanning as described above.

\section{Immunoblot Analysis of AKT and ERK}

Subconfluent cultures (10 cm dishes) of RINm5F cells were washed and incubated for 1 hour with serum-free medium and subsequently stimulated with $0.1 \mu \mathrm{g} / \mathrm{ml}$ insulin as described above. After washing with cold PBS the cells were lysed in SDS$\beta$-mercapthoethanol sample buffer supplemented with $1 \mathrm{mM}$ (PMSF), briefly sonicated and used for immunoblot analysis for phospho-AKT (Ser-473), AKT, phospho-ERK1/2 (Thr202/Tyr204) (New England Biolabs, Beverly, MA) or ERK1/2 (Santa Cruz, Santa Cruz, CA). The amount of phosphorylated protein was quantified by densitometric scanning and normalised against the total amount of protein.

\section{Statistical Analyses}

The means \pm SEM for the number of observations are given. Each observation is based on the value obtained from one separate experiment. Unpaired Student's t-tests were used to determine a statistical difference between GTK-overexpressing and control cells (when applicable, the mean value of neo- 1 and neo- 2 for each independent experiment was calculated).

\section{Results \\ Effects of GTK Overexpression on IRS-1 and IRS-2 Phosphorylation in Islets}

To study the effects of GTK on IRS-1 and IRS-2 phosphorylation in response to insulin in $\beta$ cells, serum-deprived islets isolated from control or GTKtransgenic CBA mice were stimulated with insulin for 10 minutes and IRS-1 and IRS-2 were immunoprecipitated. Similar amounts of cell lysates were used in each group as assessed by blotting for ERK1/2 (Fig. 1A) or immunoprecipitated total IRS-2 (results not shown). Insulin increased the phosphorylation of IRS- 1 and IRS- 2 in the control islets. The

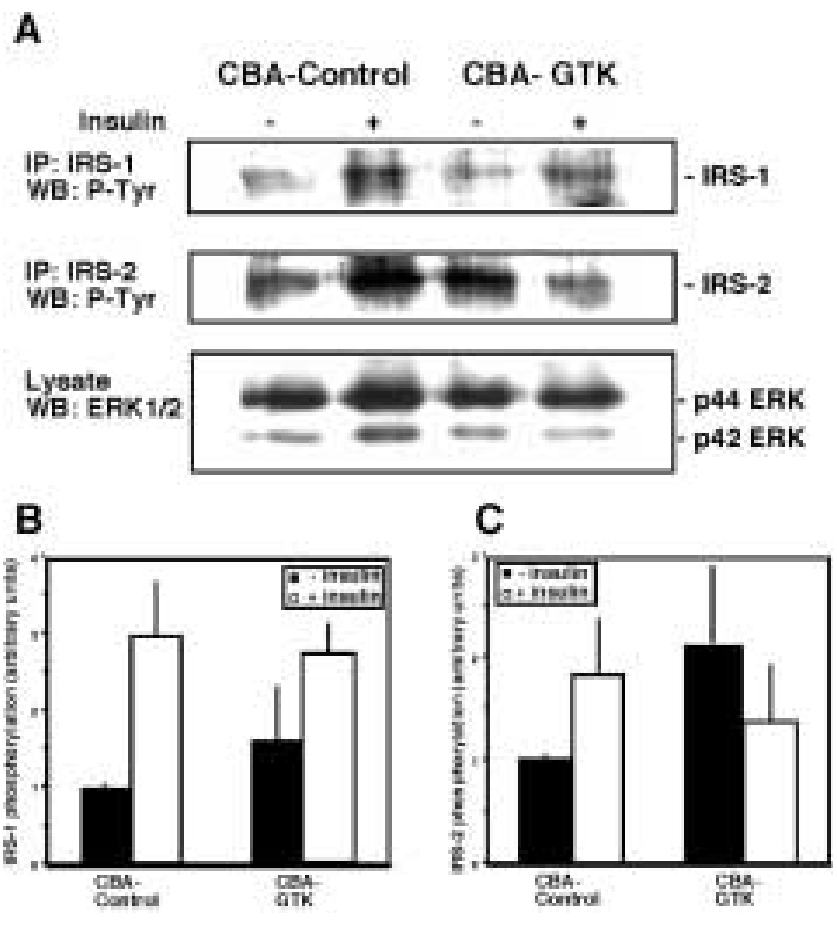

Fig. 1. Insulin-induced IRS-1 and IRS-2 phophorylation in islet cells. 2000 islets from control $(n=9)$ and GTKtransgenic $(n=6)$ mice were isolated and divided equally into two groups (1000 islets/group). The islets were serum starved for $60 \mathrm{~min}$ and stimulated with insulin dissolved in $30 \mathrm{mM} \mathrm{HCl} \mathrm{(+)} \mathrm{or} \mathrm{HCl}$ only (-) for $10 \mathrm{~min}$ or left unstimulated. The cells were lysed and subjected to immunoprecipitation for IRS-1 followed by immunoprecipitation for IRS-2. All precipitates were subjected to Western blot analysis for phosphotyrosine (P-Tyr). Cell lysate was subjected to SDSPAGE and Western blot analysis for ERK 1/2 (A). Densitometric scanning was performed and the IRS-phosphorylation normalised against the amount of lysate ERK1/2 or immunoprecipitated total IRS-2 was calculated for each group (B and C) in two separate experiments. Means \pm SEM are given. 
insulin-induced IRS-1 phosphorylation was reduced in the GTK-transgenic islets compared to the control islets (Fig 1A and B). Moreover, the basal IRS-2 tyrosine phosphorylation was increased in the GTKtransgenic islets and the insulin-induced IRS-2 phosphorylation was completely abolished in these cells, suggesting a strongly perturbed IRS-2 signalling (Fig. 1A and C).

\section{Effects of GTK Overexpression on IRS-1 and IRS-2 Phosphorylation in RINm5F Cells}

The difficulty in obtaining a sufficient number of islets to extend the observations in Fig. 1, prompted the usage of RINm5F cells, stably overexpressing myc-tagged GTK. The expression level of myc-tagged GTK was increased about three-fold compared to the endogenous p57 GTK and was similarly expressed in all GTK-transfected clones (Fig. 2). The Y504Fmutated GTK cells displayed increased GTK autophosphorylation compared to the wild type GTK, in line with previous results (2). In contrast, the Y394F-mutated GTK exhibited a 30\% reduction of the relative in vitro kinase activity compared to the wild type GTK (Fig. 2), suggesting indeed that Tyr394 is an important autophosphorylation site analogous to Tyr-416 in C-SRC. This analogy suggests that the Y394F-mutation may suppress the ability of GTK to be activated by Tyr-504 dephosphorylation (3) and thus it is conceivable that the decrease of kinase activity of this mutant may be more pronounced under conditions of in vivo activation.

IRS- 1 and IRS-2 expression levels were comparable in the different clones except for slightly lower IRS-1 levels in the GTK ${ }^{\mathrm{wt}}$ cells. The insulin-induced tyrosine phosphorylation of IRS-1 was reduced by

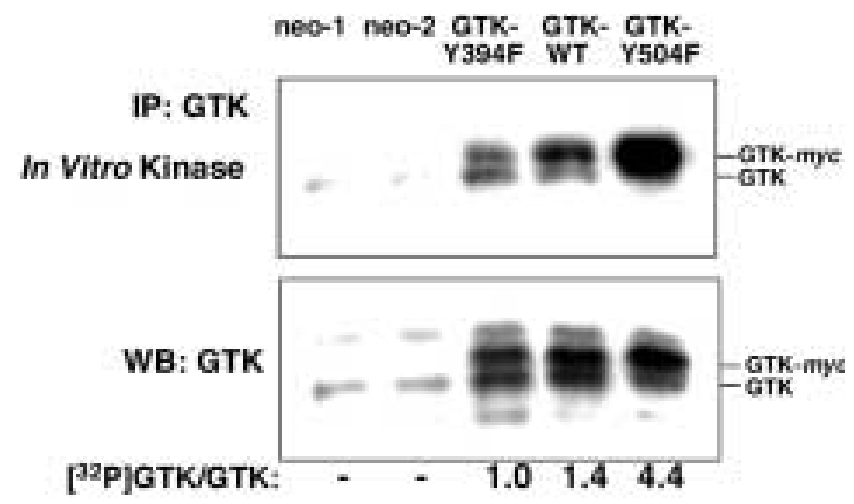

Fig. 2. In vitro kinase assay on immunoprecipitated GTK. Cell extracts from RINm5F cells, stably transfected with empty vector (neo-1 and neo-2), Y394-mutated, wild type and Y504Fmutated GTK, were immunoprecipitated with GTK-antiserum and subjected to an in vitro kinase assay for $15 \mathrm{~min}$. The reaction was subjected to SDS-PAGE, and Western Transfer. The phosphorylation was visualised by autoradiography after SDSPAGE (top) and the total amount of GTK was assessed by Western blotting (bottom). The $\left[{ }^{32} \mathrm{P}\right]$ incorporation into the myctagged GTK was assessed by densitometry and the relative amount was calculated and is indicated below each group. about $40 \%$ in RINm5F cells expressing the kinase active GTK $^{\mathrm{Y} 504 \mathrm{~F}}$, consistent with the data on GTKtransgenic islets (Fig. 3A). RINm5F cells expressing GTK $^{\mathrm{Y} 394 \mathrm{~F}}$ exhibited a pattern of responses that was similar to that of the control cells indicating that the kinase activity is of importance for the GTK-induced effect on IRS-signalling. Two separate controlclones (neo-1 and neo-2) displayed a similar degree of IRS-1 phosphorylation; thus it appears unlikely that the observed effects are due to clonal selection (results not shown). The insulin-induced IRS-2 phosphorylation, in RINm5F cells expressing both GTK $^{\mathrm{Y} 504 \mathrm{~F}}$ and $\mathrm{GTK}^{\mathrm{wt}}$, was about $50 \%$ of maximum, which was significantly reduced compared to the control cells (Fig. 3B). This was partly due to increased basal phosphorylation of IRS-2 in the GTK $^{\mathrm{Y} 504 \mathrm{~F}}$ cells.

It has been demonstrated that the adapter protein SHB associates with IRS-2 and FAK in SHBoverexpressing RINm5F cells and that insulin-induced IRS-phosphorylation is impaired in these cells (23a). It was therefore examined if SHB co-precipitates with the IRS-proteins in RINm5F cells expressing GTK. SHB was found to associate with IRS-1 in all the GTK-overexpressing clones both in the absence and presence of insulin but the basal associationlevel was higher in the $\mathrm{GTK}^{\mathrm{wt}}$ and $\mathrm{GTK}^{\mathrm{Y} 504 \mathrm{~F}}$ cells (Fig. 3A). An association between SHB and IRS-2 in the GTK $^{\mathrm{Y} 504 \mathrm{~F}}$ cells was also observed (Fig. 3B).

\section{Effect of GTK Overexpression on PI3K Activity}

Since PI3K is a downstream effector of IRS-1 and IRS-2, insulin-stimulated PI3K activity in phosphotyrosine immunoprecipitates from RINm5F cells was assessed. The data on PI3K activity reflects the combined IRS-1 and IRS-2 phosphorylation data (Fig. 3) in that GTK overexpression reduces the response to insulin. The basal activity of PI3K was significantly elevated in the GTK ${ }^{\mathrm{wt}}$ and the GTK ${ }^{\mathrm{Y} 504 \mathrm{~F}}$ clones (Fig. 4A and B) and both GTK $^{\mathrm{wt}}$ and GTK ${ }^{\mathrm{Y} 504 \mathrm{~F}}$ exhibited diminished PI3K activation in response to insulin compared to the control clones (Fig. 4C).

\section{Effect of GTK Overexpression on AKT and ERK1/2 Phosphorylation}

Insulin-mediated activation of PI3K induces elevated contents of 3'phosphorylated phosphoinositides, which results in activation of AKT by the phosphorylation of Thr-308 and Ser-473 (16). The phosphorylation of AKT (on Ser-473) relative the total amount of AKT present in the cell lysates was low in all clones, although there was a tendency to higher basal levels in the GTK-expressing clones (Fig. 5A, top). Insulin induced a three-fold increase in the control-clones but only a two-fold increase in the GTK $^{\mathrm{wt}}$ and GTK $^{\mathrm{Y} 504 \mathrm{~F}}$ clones, resembling the PI3K activation pattern (Fig. 5A, bottom).

ERK $1 / 2$ is activated upon insulin-receptor activation through phosphorylation of Thr-202 and 

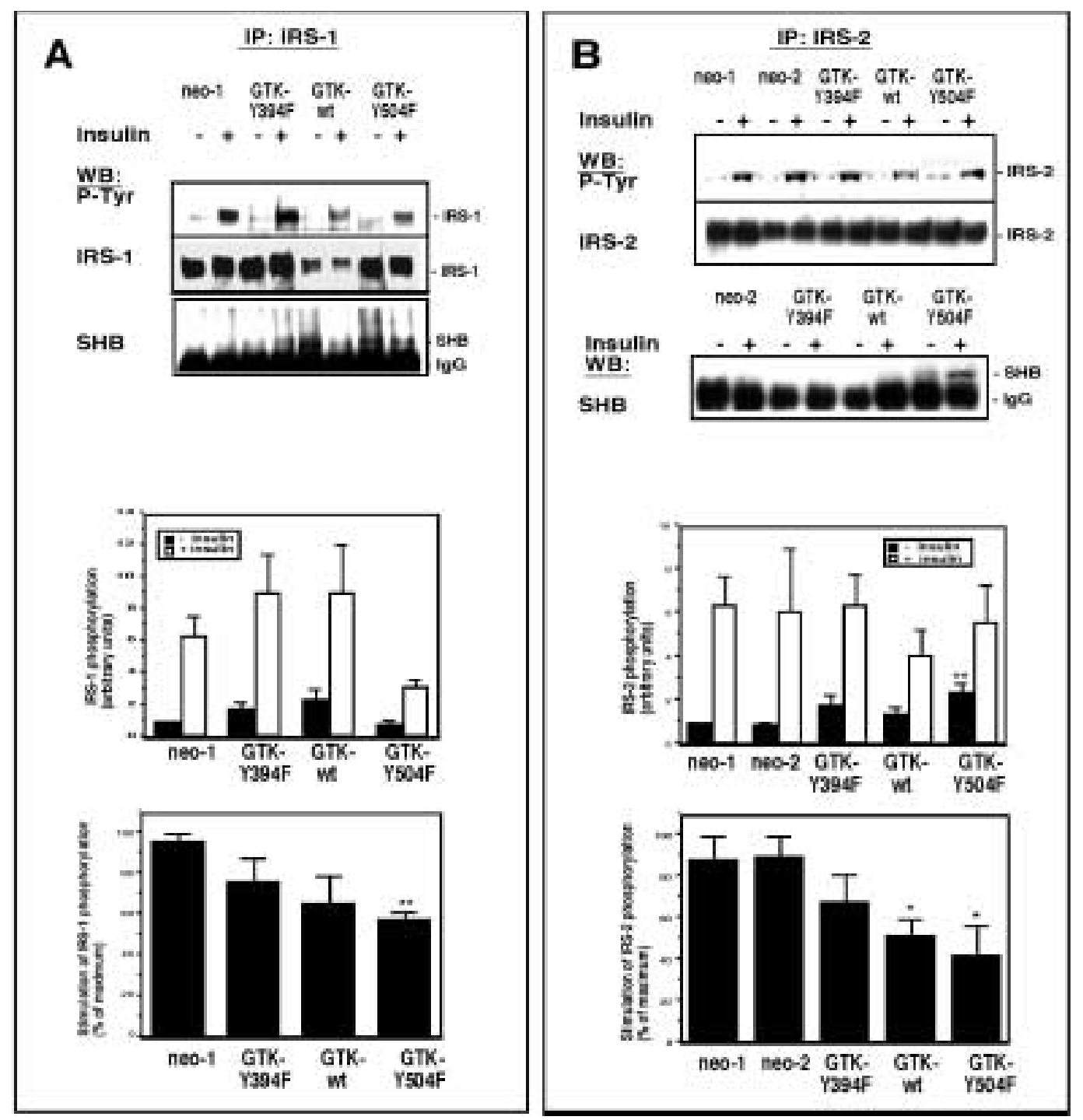

Fig. 3. Insulin-induced IRS-1 and IRS-2 phophorylation in RINm5F cells. Serum-starved control (neo-1 and neo-2) RINm5F cells or RINm5F cells overexpressing GTK (GTK ${ }^{\mathrm{wt}}$, GTK ${ }^{\mathrm{Y} 394 \mathrm{~F}}$ and GTK $^{\mathrm{Y} 504 \mathrm{~F}}$ ) were stimulated with insulin as described above. The cells were lysed, immunoprecipitated for IRS-1 or IRS-2 and subjected to Western blot analysis for phosphotyrosine (P-Tyr), IRS-1, IRS-2 and SHB. (A). Tyrosine phosphorylated IRS-1 was detected as a $185 \mathrm{kDa}$ band (top). Densitometric scanning of tyrosinephosphorylated and total amount of IRS-1 and the mean IRS-1 phosphorylation normalised against the total amount of IRS-1 protein was calculated (middle). The stimulation of IRS-1 phosphorylation in response to insulin was calculated as the percent of maximum stimulation, the largest fold increase of IRS-1 phosphorylation in each experiment was set to $100 \%$ (bottom) (B). Tyrosine phosphorylated IRS-2 was detected as a $200 \mathrm{kDa}$ band (top). Densitometric scanning of tyrosine-phosphorylated and total amount of IRS-2 and the mean phosphorylation normalised against the total amount of IRS-2 was calculated (middle). The stimulation of IRS-2 phosphorylation in response to insulin was calculated as the percent of maximum stimulation as described above (bottom). Bars are means \pm SEM from 4-5 independent experiments. ${ }^{*}, \mathrm{p}<0.05$ and ${ }^{* *}, \mathrm{p}<0.01$ when compared with corresponding value of RINm5F-control (neo).

Tyr-204 by MEK. GTK ${ }^{\mathrm{Y} 504 \mathrm{~F}}$ cells showed an increased basal phosphorylation of ERK resulting in a reduced insulin-induced ERK activity compared to the neo cells (Fig. 5B). This is in line with previous results showing an increased ERK 1/2 activity in GTK-transgenic islets (4).

\section{Effect of GTK Overexpression on SHB Phosphorylation}

Because SHB was found to associate with IRS-1 and IRS-2 in the GTK ${ }^{\mathrm{Y} 504 \mathrm{~F}}$ expressing cells and since
RINm5F cells overexpressing SHB show reduced insulin-induced IRS phosphorylation consistent with what is observed in the GTK-expressing cells, SHBphosphorylation in response to insulin was studied in RINm5F cells. GTK ${ }^{\mathrm{Y} 504 \mathrm{~F}}$ cells exhibited increased SHB phosphorylation mainly in the presence of insulin compared to the control cells and this was accompanied by an increased association of SHB with IRS-2 (Fig 6A). Likewise, the tyrosine phosphorylation of $\mathrm{SHB}$ was increased in the RIN ${ }^{\mathrm{Y} 504 \mathrm{~F}}$ cells compared 


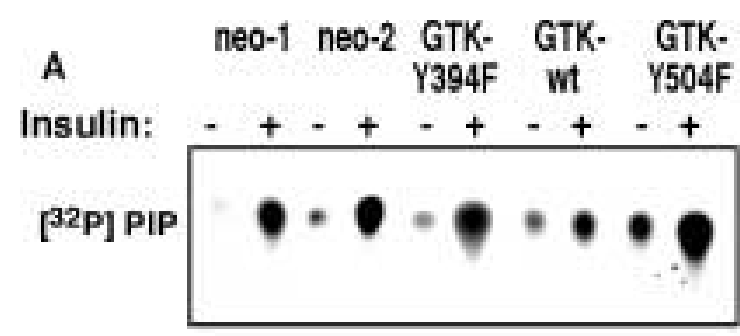

B

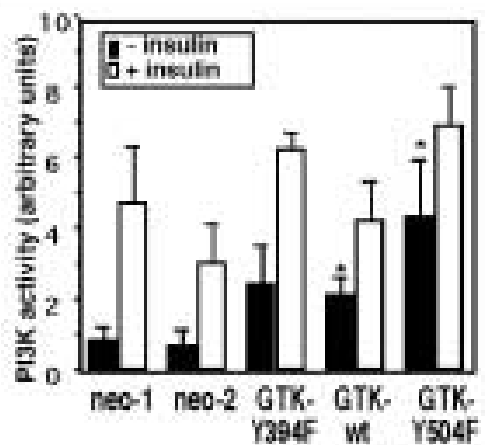

C

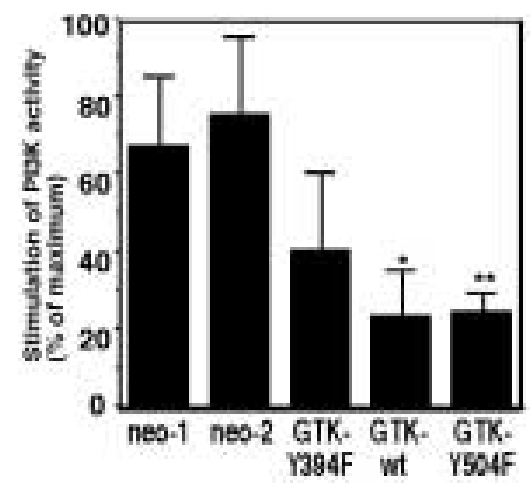

Fig. 4. Insulin-induced PI3K activity in RINm5F cells. (A) Cells were stimulated with insulin as described above, immunoprecipitated with phosphotyrosine antibody (PY20) and subjected to an in vitro kinase reaction using PI as a substrate for PI3K. Phospholipids were then separated on silica TLC plates and the radioactive product (PIP) was detected with autoradiography (A) and quantified by densitometric scanning (B). The stimulation of PI3K activity as percent of maximum was calculated as described above $(C)$. Bars are means \pm SEM from 4 independent experiments. ${ }^{*}, \mathrm{p}<0.05$ and ${ }^{* *}, \mathrm{p}<0.01$ when compared with corresponding value of RINm5F-control (neo-1 and neo-2).

with control cells when cultured in $10 \%$ serum (Fig. 6B). The phosphotyrosine blot also revealed two prominent phosphorylated proteins of about $125 \mathrm{kDa}$ and $250 \mathrm{kDa}$ that co-immunoprecipitated with SHB in an insulin-dependent manner and to a higher extent in the GTK-expressing cells, than in the control cells. Moreover, the basal association between SHB and these proteins was elevated in the GTK-Y504F cells. To assess if the $125 \mathrm{kDa}$ band could be FAK, the blot was stripped and reprobed with an antibody against phospho-FAK (Tyr-397), verifying the $125 \mathrm{kDa}$ band as tyrosine phosphorylated FAK and confirming the relative pattern of co-immunoprecipitation of this band with SHB (results not shown).

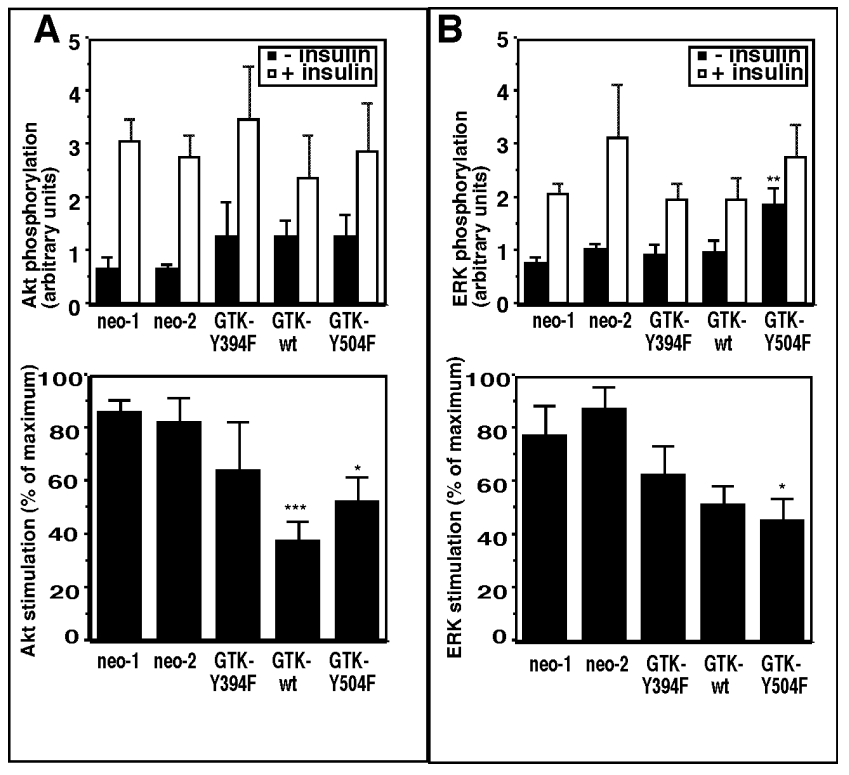

Fig. 5. Insulin-induced activation of AKT and ERK1/2 in RINm5F cells. Serum-starved control (neo-1 and neo-2) RINm5F cells and RINm5F cells overexpressing GTK (GTK ${ }^{\mathrm{wt}}$, $\mathrm{GTK}^{\mathrm{Y} 394 \mathrm{~F}}$, GTK ${ }^{\mathrm{Y} 504 \mathrm{~F}}$ ) were stimulated with insulin as described above. The cells were lysed in SDS- $\beta$-mercaptoethanol sample buffer and subjected to Western blot analysis for phospho-AKT, AKT, phospho-ERK1/2 and ERK1/2. (A) Densitometric scanning of phosphorylated AKT was performed and the mean normalised against the total amount of AKT was calculated from 4 independent experiments. The stimulation of AKT in response to insulin was calculated as the percent of maximum stimulation. (B) Densitometric scanning of phosphorylated ERK 1/2 was performed and the mean normalised against the total amount of ERK 1/2 was calculated. The stimulation of ERK 1/2 in response to insulin was calculated as the percent of maximum stimulation. Bars are means \pm SEM from 5 independent experiments. ${ }^{*} \mathrm{p}<0.05,{ }^{* *} \mathrm{p}<0.01$ and ${ }^{* * *} \mathrm{p}<0.001$ when compared with corresponding value of RINm5F-control (neo-l and neo-2).

\section{SHB is a GTK Substrate in COS-7 Cells}

It has previously been shown that GTK-overexpression in PC12 cells induces strong phosphorylation of SHB (5), in line with the present findings and it has therefore been suggested that SHB is a downstream effector of GTK. It has, however, not been established if these two proteins interact or if GTK directly phosphorylates SHB. We therefore analysed the ability of GTK and SHB to associate when overexpressed in COS-7 cells (Fig. 7). The GTK- or SHBspecific bands were weak or undetectable in the non-transfected COS-7 cells, whereas $g t k$-transfected and $s h b$-transfected cells expressed large amounts of respective protein. Cells transfected with equal amounts of $s h b$ and $g t k$ exhibited a strong association between the two proteins, as assessed by precipitating GTK and SHB and monitoring co-precipitation by blotting for SHB and GTK respectively. Moreover, SHB, which was unphosphorylated in the absence of GTK, exhibited a strong phosphorylation when co-transfected with GTK. These results clearly 

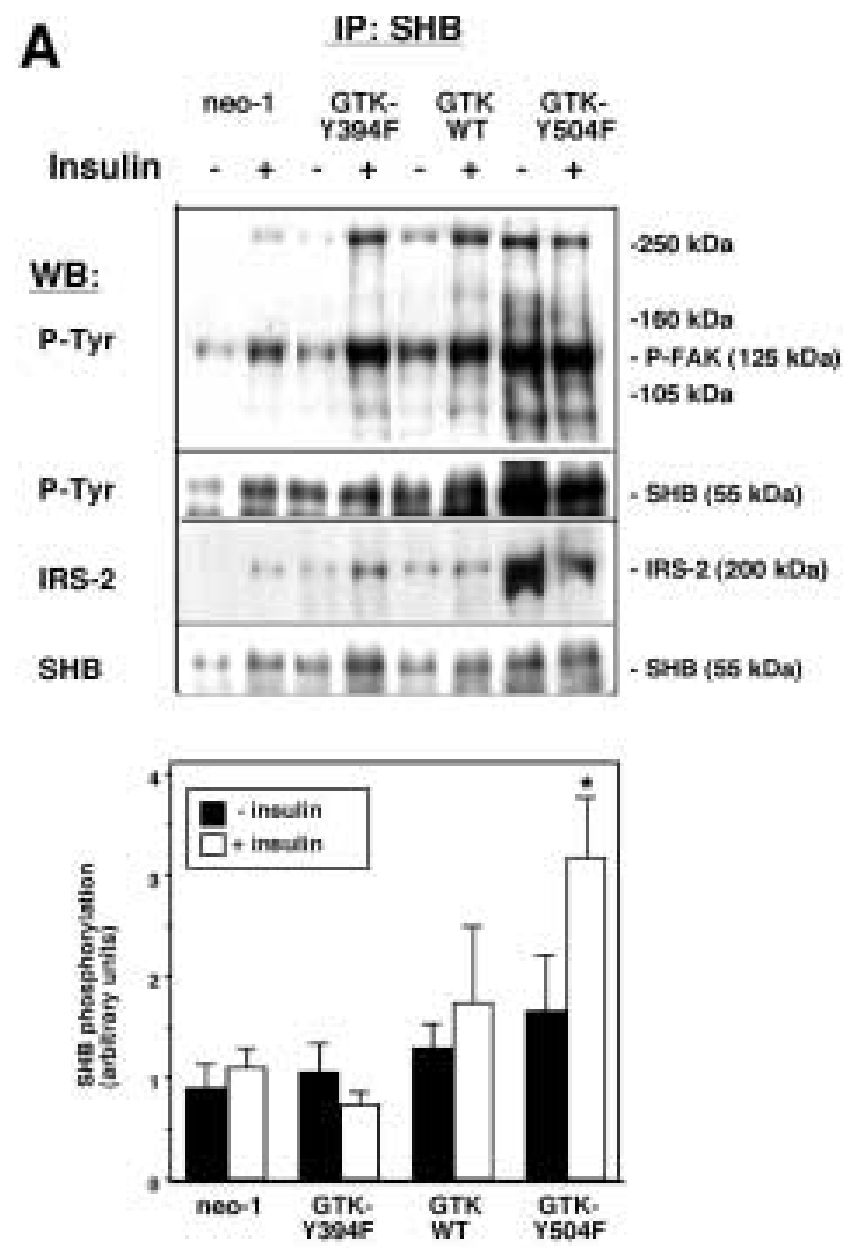

B

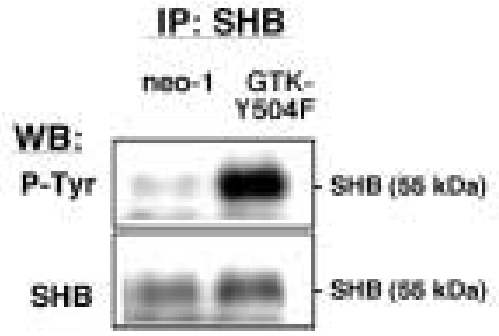

Fig. 6. Insulin-induced SHB-phosphorylation in RINm5F cells. (A) Serum-starved control (neo) RINm5F cells and RINm5F cells overexpressing GTK were stimulated with insulin as described above. The cells were then washed, lysed and immunoprecipitated for SHB and subjected to Western blot analysis for phosphotyrosine (P-Tyr), SHB, IRS-2 and phospho-FAK. Densitometric scanning of phosphorylated SHB was performed and the mean normalised against the total amount of SHB was calculated from 4 independent experiments. Bars are means \pm SEM.

${ }^{*} \mathrm{p}<0.05$ when compared with corresponding value of RINm5Fcontrol (neo-1). (B) Cells (neo-1 and GTK ${ }^{\mathrm{Y} 504 \mathrm{~F}}$ ) cultured in a $10 \%$ serum medium were immunoprecipitated for SHB and subjected to Western blotting for phosphotyrosine (P-Tyr) and SHB.

show that GTK can bind and phosphorylate SHB, and could explain previous and present results showing increased SHB phosphorylation in GTKoverexpressing cells.

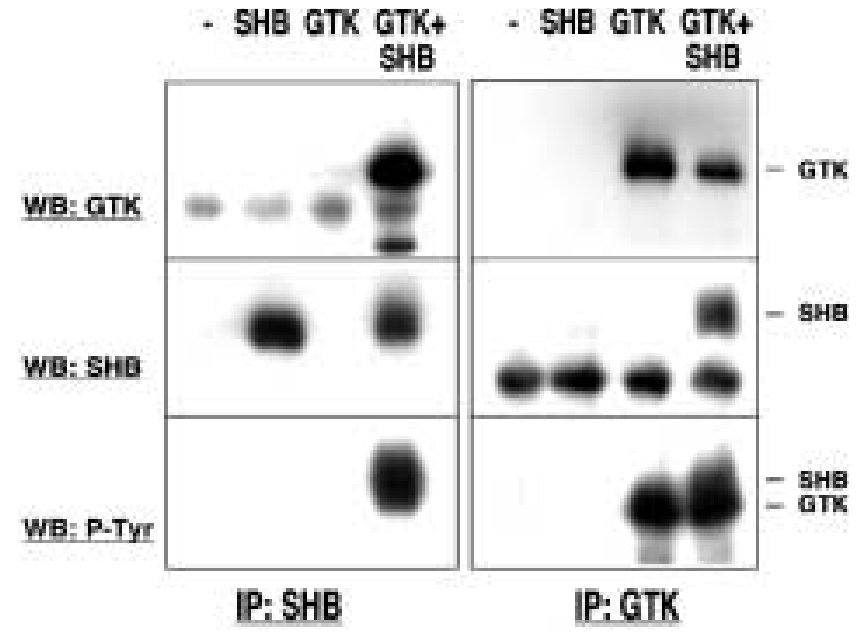

Fig. 7. GTK associates with and phosphorylates SHB. COS-7 cells were transfected with expression vectors encoding gtk or $s h b$ or co-transfected with equal amounts of each construct. Cell lysates were subjected to immunoprecipitation (IP) with anti- SHB (left panel), or anti-GTK (right panel) antibodies followed by immunoblotting (WB) with anti-GTK (top), anti-SHB (middle) and anti-phosphotyrosine (P-Tyr, bottom) antibodies.

\section{Discussion}

This study shows an impaired insulin-induced IRS-1 and IRS-2 signalling in RINm5F cells and islet cells as a consequence of overexpressing the tyrosine kinase GTK. A 40\% reduction in insulin-induced activation of signal-transduction pathways downstream of the insulin-receptor, including IRS-1, IRS-2, PI3K, AKT and ERK 1/2 was observed in cells expressing wild-type and the more kinase active Y504F-mutated GTK. In addition the results show an increased association between SHB, IRS-2, IRS-1 and FAK mainly in the GTK ${ }^{\mathrm{Y} 504 \mathrm{~F}}$ cells. The GTKinduced changes in insulin signalling depended on the kinase activity of GTK since cells expressing Y394F-mutated GTK showed responses to insulin that were insignificantly altered compared to the control cells, whereas the $\mathrm{GTK}^{\mathrm{Y} 504 \mathrm{~F}}$-expressing clones exhibited the most prominent effects on IRSsignalling.

In $\mathrm{GTK}^{\mathrm{wt}}$ and $\mathrm{GTK}^{\mathrm{Y} 504 \mathrm{~F}}$ expressing RINm5F cells the PI3K activation was reduced due to an increased basal activity, similar to what is observed in IRS $-1^{-1+}$ IRS $-2^{-1+}$ cells (26), suggesting that the reduction of both IRS- 1 and IRS- 2 activation could be important for this response. However, present and previous results implicate that IRS-2 is the main target for GTK in vivo. For instance, GTK-transgenic islet cells showed a strongly perturbed IRS-2 phosphorylation, with elevated basal levels and a blunted response to insulin, whereas IRS-1 phosphorylation was moderately affected. GTK-transgenic mice exhibit a significantly increased $\beta$-cell mass, which may be a consequence of increased signalling via IRS-2, since IRS-2, in contrast to IRS- 1 , is predominantly expressed in the $\beta$ cells and has been shown 
to regulate $\beta$-cell growth (21). IRS-2 may induce $\beta$-cell growth by activating the RAS-ERK pathway, since this pathway is well known to promote proliferation. Indeed, the increased basal ERK activity in the $\mathrm{GTK}^{\mathrm{Y} 504 \mathrm{~F}}$ cells and in GTK-transgenic islets (4) supports this hypothesis. It has recently been suggested that negative feedback regulation of IRS-activity by, for instance, ERK, AKT and PKC- $\zeta$ (27-29), is important in insulin signal transduction. Taking this into account, it is possible that GTK is a potent activator of IRS-signalling in the absence of insulin and that the reduced responsiveness to insulin in the transgenic islets and the RINm5F clones reflects the augmentation of one or more feedback regulatory mechanisms under these conditions. Consistent with this hypothesis is the increased basal activity of IRS-2, PI3K, AKT and ERK 1/2 as well as the increased association between SHB and FAK with IRS-2 observed in GTK ${ }^{\mathrm{Y} 504 \mathrm{~F}}$ expressing cells.

Present and previous findings suggest that GTK may signal via SHB to exercise at least some of its effects. The observation that GTK induces phosphorylation of SHB and its association with FAK in RINm5F cells is consistent with a previous study on GTK overexpressing PC12 cells (5). Moreover, SHBoverexpression has recently been shown to induce similar perturbations in IRS-signalling in insulin producing cells as the GTK-overexpressing cells, including reduced insulin-induced activation of IRS-1, IRS-2 and PI3K as well as an induced complexformation between SHB, IRS-2 and FAK (23a). Interestingly, transgenic CBA mice expressing GTK under the control of the insulin promoter show a phenotype similar to SHB-transgenic CBA mice, thus both exhibit a larger relative $\beta$-cell area and increased cytokine-induced islet cell death $(4,8)$. We presently show, for the first time, that GTK associates with and phosphorylates SHB. The strong binding and the fact that SHB was unphosphorylated in the absence of GTK, indicate that SHB is a specific substrate for GTK and that these two proteins associate directly without any intermediate protein. This interaction may be accomplished by the proline-rich region of SHB binding to the SH3 domain of GTK. Moreover, one or more of the putative tyrosine phosphorylation sites in SHB may bind the SH2 domain of GTK. Tyr-333 in SHB is of particular interest since the amino acid sequence following this tyrosine is similar to that of Tyr-504 in GTK, namely SerAsp-Pro and Ser-Asp-Thr respectively $(1,30)$. Since phosphorylation of Tyr-504 negatively regulates GTK kinase activity, by binding to the $\mathrm{SH} 2$ domain of the same molecule, it is possible that SHB may activate GTK by competing with Tyr-504 for the binding to the GTK SH2 domain. Y504F-mutated GTK may, due to its open configuration, exhibit constitutive association with SHB resulting in increased SHB phosphorylation.

In summary, we would like to present the following hypothetical model for GTK-induced disturbances in IRS-signalling: Kinase active GTK, when overexpressed in insulin producing cells, associates with and phosphorylates SHB. This results in the recruitment of other signalling molecules, such as IRS-1, IRS-2 and FAK, to the complex, which induces phosphorylation of IRS-2 and activation of the downstream RAS-ERK and PI3K-AKT pathways. The constitutive activation of IRS-2-pathways in GTK-expressing cells induces negative feedback regulation of IRS-1 and IRS-2 activity by, for instance, ERK, AKT, and subsequently impairs insulin-induced activation of these pathways. The present results might explain previous findings showing a larger $\beta$-cell mass in GTK-transgenic mice and may contribute to the understanding of the pathophysiology of insulin-resistance in diseases such as diabetes and obesity.

\section{Acknowledgements}

We thank Ing-Britt Hallgren and Ing-Marie Mörsare for excellent technical assistance. This work was supported by the Juvenile Diabetes Research Foundation, the Swedish Medical Research Council (31x10822), the Swedish Diabetes Association, the NovoNordisk Foundation and the Family Ernfors Fund.

\section{References}

1. Öberg-Welsh C, Welsh M. (1995) Cloning of BSK, A murine FRK homologe with a specific pattern of tissue distribution. Gene. 152: 239-242.

2. Annerén C, Welsh M. (2000) Role of the Bsk/Iyk non-receptor tyrosine kinase for the control of growth and hormone production in RINm5F cells. Growth Factors. 17: 233-247.

3. Kmiecik TE, Shalloway D. (1987) Activation and suppres-

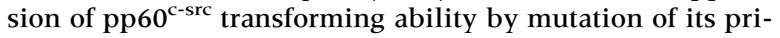
mary sites of tyrosine phosphorylation. Cell. 49: 65-73.

4. Annerén C, Welsh M. (2001) Increased cytokine-induced cytotoxicity of pancreatic islet cells from transgenic mice expressing the Src-like tyrosine kinase GTK. Mol Med. 7: 301-310.

5. Annerén C, Reedquist KA, Bos JL, Welsh M. (2000) GTK, a Src-related Tyrosine Kinase, Induces Nerve Growth Factorindependent Neurite Outgrowth in PC12 Cells through Activation of the Rapl Pathway. Relationship to Shb tyrosine phosphorylation and elevated levels of focal adhesion kinase. J Biol Chem. 275: 29153-29161.

6. Welsh M, Mares J, Karlsson T, Lavergne C, Breant B, Claesson-Welsh L. (1994) Shb is a ubiquitously expressed Src homology 2 protein. Oncogene. 9: 19-27.

7. Welsh M, Annerén C, Lindholm C, Kriz V, Öberg-Welsh C. (2000) Role of tyrosine kinase signaling for beta-cell replication and survival. Ups $J$ Med Sci. 105: 7-15.

8. Welsh M, Christmansson L, Karlsson T, Sandler S, Welsh N. (1999) Transgenic mice expressing Shb adaptor protein under the control of rat insulin promoter exhibit altered viability of pancreatic islet cells. Mol Med. 5: 169-180.

9. Rothenberg PL, Willison LD, Simon J, Wolf BA. (1995) Glucose-induced insulin receptor tyrosine phosphorylation in insulin-secreting beta-cells. Diabetes. 44: 802-809. 21

10. Xu GG, Rothenberg PL. (1998) Insulin receptor signaling in the beta-cell influences insulin gene expression and insulin content: evidence for autocrine beta-cell regulation. Diabetes. 47: 1243-1252.

11. Ogawa W, Matozaki T, Kasuga M. (1998) Role of binding proteins to IRS-1 in insulin signalling. Mol Cell Biochem. 182: 13-22. 
12. Yenush L, White MF. (1997) The IRS-signalling system during insulin and cytokine action. BioEssays. 19: 491-500.

13. Combettes-Souverain M, Issad T. (1998) Molecular basis of insulin action. Diabetes Metab. 24: 477-489.

14. Avruch J. (1998) Insulin signal transduction through protein kinase cascades. Mol Cell Biochem. 182: 31-48.

15. White MF, Yenush L. (1998) The IRS-signaling system: a network of docking proteins that mediate insulin and cytokine action. Curr Top Microbiol Immunol. 228: 179-208.

16. Datta SR, Brunet A, Greenberg ME. (1999) Cellular survival: a play in three Akts. Genes Dev. 13: 2905-2927.

17. Lamothe B, Baudry A, Desbois P, et al. (1998) Genetic engineering in mice: impact on insulin signalling and action. Biochem J. 335: 193-204.

18. Kadowaki T. (2000) Insights into insulin resistance and type 2 diabetes from knockout mouse models. J Clin Invest. 106: 459-465. 22

19. Araki E, Lipes MA, Patti ME, et al. (1994) Alternative pathway of insulin signalling in mice with targeted disruption of the IRS-1 gene. Nature. 372: 186-190.

20. Tamemoto H, Kadowaki T, Tobe K, et al. (1994) Insulin resistance and growth retardation in mice lacking insulin receptor substrate-1. Nature. 372: 182-186.

21. Withers DJ, Gutierrez JS, Towery H, et al. (1998) Disruption of IRS-2 causes type 2 diabetes in mice. Nature. 391: 900-904.

22. Kulkarni RN, Brüning JC, Winnay JN, Postic C, Magnuson MA, Kahn CR. (1999) Tissue-specific knockout of the insulin receptor in pancreatic $\beta$ cells creates an insulin secretory defect similar to that in type 2 diabetes. Cell. 96: 329-339.

23a.Welsh N, Makeeva N, Welsh M. (2002) Overexpression of the Shb SH2 domain-protein in insulin-producing cells leads to altered signaling through the IRS-1 and IRS-2 proteins. Mol. Med. 8: 694-703.

23. Öberg-Welsh C, Annerén C, Welsh M. (1998) Mutation of C-terminal tyrosine residues Y497/Y504 of the Src-family member Bsk/Iyk decreases NIH3T3 cell proliferation. Growth Factors. 16: 111-124.

24. Karlsson T, Songyang Z, Landgren E, et al. (1995) Molecular interactions of the Src homology 2 domain protein Shb with phosphotyrosine residues, tyrosine kinase receptors and Src homology 3 domain proteins. Oncogene. 10: 1475-1483.

25. Traynor-Kaplan AE, Thompson BL, Harris AL, Taylor $\mathrm{P}$, Omann GM, Sklar LA. (1989) Transient increase in phosphatidylinositol 3,4-bisphosphate and phosphatidylinositol trisphosphate during activation of human neutrophils. J Biol Chem. 264: 15668-15673.

26. Withers DJ, Burks DJ, Towery HH, Altamuro SL, Flint CL, White MF. (1999) Irs-2 coordinates Igf-1 receptor-mediated beta-cell development and peripheral insulin signalling. Nature Genet. 23: 32-40.

27. De Fea K, Roth RA. (1997) Modulation of insulin receptor substrate-1 tyrosine phosphorylation and function by mitogen-activated protein kinase. J Biol Chem. 272: 31400-31406.

28. Li J, De Fea K, Roth RA. (1999) Modulation of insulin receptor substrate-1 tyrosine phosphorylation by an Akt/phosphatidylinositol 3-kinase pathway. J Biol Chem. 274: 9351-9356.

29. Ravichandran LV, Esposito DL, Chen J, Quon MJ. (2000) Protein kinase $C-\zeta$ phosphorylates IRS-1 and impairs its ability to activate PI 3-kinase in response to insulin. $\mathrm{J}$ Biol Chem.

30. Lindholm CK, Frantz JD, Shoelson SE, Welsh M. (2000) Shf, a Shb-like adapter protein, is involved in PDGF- $\alpha$-receptor regulation of apoptosis. Biochem Biophys Res Commun. 278: 537-543. 